Katotohanan sa likod ng sandaang damit: sipat-suri sa mga isyung pangkahirapan na nakapaloob sa akda ni Fanny A. Garcia

Canillas, Krisley Iris R.

Leyte Normal University, Philippines (krisleyiriscanillas@gmail.com)

Acala, Michell

Leyte Normal University, Philippines (michellet_acala@lnu.edu.ph)

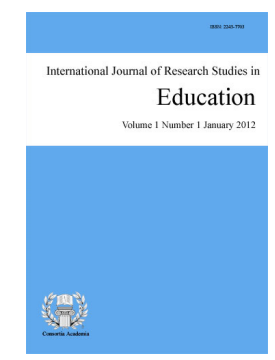

ISSN: 2243-7703 Online ISSN: 2243-7711

OPEN ACCESS

\title{
Abstract
}

Literature is considered as a reflection of various societal issues through the author's creative use of literary elements such as symbolism, theme, characters, and others. The study of literature introduces man to the realities of the world as well as the different problems of society. At present, poverty is deemed to be one of the country's greatest problems that affect the lives of poor Filipino families. This study is a qualitative research that utilized the content analysis approach. The researchers used the literary theories in analyzing the short story titled "Sandaang Damit" written by Fanny Garcia. The analysis aimed to identify the theme, symbolism, and characters of the story that depict the realities of people who experience poverty in the context of a Filipino society. This study also aimed to analyze the different societal issues relative to the country's problem on poverty. Based on the results of the study, the short story reflects the different struggles of poor Filipinos in the midst of poverty due to several factors such as unemployment, health-related problems, and social discrimination. The researchers recommend the need to formulate more programs on health, employment, and education that would help every poor Filipino family to rise amidst poverty.

Keywords: poverty, society, Filipinos, problems, literature 


\section{Katotohanan sa likod ng sandaang damit: sipat-suri sa mga isyung pangkahirapan na nakapaloob sa akda ni Fanny A. Garcia}

\section{Introduksyon}

Maraming kabataan sa kasalukuyan ang kakikitaan ng matayog na pangarap sa buhay. Ang ilan ay patuloy na nagsusumikap sa kabila ng iba't ibang hamon. Samantala, malaki ang papel na ginagampanan ng panitikan bilang repleksyon ng pamumuhay at hangarin ng bawat tao. Ayon kina Belvez et al. (2006), ang pag-aaral sa panitikan ay maituturing na pagkilala sa ating lahi. Nakikita ang mga napapanahong kalagayan ng bawat miyembro ng lipunan sa pamamagitan ng paglikha ng mga karakter na simbolo ng iba't ibang aspeto sa buhay.

Sa pag-aaral ng Panitikang Filipino, hindi lamang pagkakakilanlan ng lahi ang ganap na nauunawan ng lahat kundi maging ang mga suliraning panlipunan na patuloy na bahagi ng buhay ng mga mamamayan sa lipunan. Isa ang kahirapan sa mga suliranin ng bansa na mapahanggang ngayon ay hinahanapan ng solusyon. Gayunpaman, maraming mga manunulat ang nagpapahayag ng kanilang karanasan, pagkadismaya, hinaing, at panawagan kaugnay sa ganitong problemang panlipunan ng bansa sa pamamagitan ng pagsulat ng iba't ibang kathang pampanitikan. Ang mga tauhang nalilikha ng isang manunulat ng panitikan ay sumisimbolo sa aktwal na karanasan ng mga tao sa lipunan. Ang mga tauhang ito ang nagpapakilos sa damdamin at isipan ng mambabasa upang makabuo ng aksyon tungo sa iisang hangarin. Ang mainam na pagbuo ng manunulat ng tauhan at iba pang elemento ng katha ay susi upang ganap na magkaroon ng panlasa ang obrang pampanitikan. Dagdag pa nina Panganiban et al. (2002), ang panitikan ay may kakayahang gisingin ang damdamin ng mga mambabasa upang makisangkot sa mga kasalukuyang suliranin ng buhay-bansa, tungo sa pagbuo ng aksyon sa ikalulutas ng ilan sa mga suliranin.

Sa mga bansang Asyano, ang diskriminasyon ay kadalasang nangyayari sa mga paaralan (Chen, 2015) at 4 sa 10 mga mag-aaral na Pilipino ang nakararanas nito dahil sa kanilang nakatatawang pangalan, amoy sa katawan, at pananamit (Sanapo, 2017). Sa pag-aaral na isinagawa nina Fleming at Jacobsen (2009), sa 19 na mahihirap na bansa kasama ang Pilipinas, umabot ng $37.1 \%$ ang mga mag-aaral na nakararanas ng diskriminasyon sa sekondarya. Sinuportahan naman ito ng pag-aaral ni Gabiana (2017) na nagpapahayag na ang mga mahihirap na mag-aaral ang kadalasang biktima ng ganitong isyu dahil sa kawalan ng kakayahan sa maayos na pananamit.

Kaya naman, ang pagsusuring ito ay nakatuon sa pagsipat sa akda ni Fanny Garcia na pinamagatang Sandaang Damit. Ang akda ay umiikot sa kwento ng kahirapan at mga epekto nito. Mahalaga ang pagsusuri nito para sa mga mag-aaral na may kursong panitikan, mga guro na nagtuturo ng panitikan, at maging sa lipunan. Maipapahayag ng mga manunuri ang katotohanan na pinagdadaanan ng isang tao sa likod ng kanyang pananamit at kung paano ito nakaaapekto sa lipunang kinabibilangan. Magbibigay ng mas malalim na pag-unawa ang pagsusuring ito kung ano ang halaga ng isang damit sa tao batay sa sinuring akda. Magsisilbi itong daan upang makita ang reyalidad sa lipunan at makatutulong din upang mas mapaunlad ang kaalaman sa panitikan. Magsisilbing tiyak na layunin ang pagtukoy sa (1) elemento at (2) isyung pankahirapan na nakapaloob sa akda ni Fanny A. Garcia.

\subsection{Layunin}

Ang maikling kwento ni Fanny A. Garcia na pinamagatang "Saandaang Damit" ay sumasalamin sa mga isyung pangkahirapan sa lipunan. Magsisilbing mga tiyak na layunin ang mga sumusunod:

\section{Elemento}

1.1 Tauhan 
1.2 Tema

\subsection{Simbolismo}

2. Isyung pangkahirapan na masasalamin sa akda

\subsection{Saligang Teoretikal}

Ang akda ay susuriin ayon sa mga teorya ng marxismo, realismo, imahismo, at sosyolohikal. Sa pamamagitan ng mga teroyang ito, masusuri ang mga elemento tulad ng tauhan, tema, simbolismo, at ang mga isyung pangkahirapan na masasalamin sa akdang "Sandaang Damit" ni Garcia. Ang teorya ng Marxismo ay nagpapakita ng kasaysayan ng malaking pagkakaiba ng mga tao batay sa katayuan nila sa lipunan (Birchall, 1977). Ito ay pinangunahan nina karl Marx at Frederick Engels noong kalagitnaan ng ika-19 siglo na naglalayong baguhin at gisingin ang kamalayan ng mga manggagawang naapi dahil sa kapitalismo. Dagdag pa ni Birchall (1977), ang mga mayayaman ay may kakayahang baguhin ang ganitong sistema upang mawala ang tunggalian ng mga tao sa anumang uri ng katayuan sa lipunan.

Ang teoryang realismo ay naglalayong ipakita ang reyalidad sa mga karanasan ng tao at lipunan sa isang makatotohanan pangyayari sa isang akda. Ito ay unang ginamit sa Pransya noong $1826 \mathrm{ng}$ Mercure francias du XIX siecle upang bigyan ng tuon ang buhay ng mga mabababang uri ng tao sa lipunan. Naging masigla ang pagtalakay sa teoryang ito sa unang bahagi ng 1900 dahil na rin sa paglaban sa romantisismo sa Alemanya. Dagdag pa ni Taghizadeh (2014), ipinapakita ng realismo ang ugnayan ng mga salita sa totoong buhay sa pamamagitan ng representasyon ng kaisipan at kasaysayan ng tao.

Samantala, ang teoryang imahismo ay may layuning magpinta ng imahen na higit na magpapahayag ng damdamin, kaisipan, at ideya gamit ang malayang pagpili ng paksa at paggamit ng mga simbolismo. Ayon sa pag-aaral nina Jurafsky at Kao (2015), malaki ang naging epekto ng Imahismo sa modernong literatura na naglalayong maipakita at hindi isalaysay ang isang obra maestra.

Ang teoryang sosyolohikal naman ay may pananaw na may impluwensiya ang lipunang ginagalawan ng manunulat sa produkto ng kanutang malikhaing pag-iisip. Ito ay magpapakita ng ugnayan ng likhang-sining at lipunan. Tinatalakay sa pananaw na ito ang mga kalagayang sosyal at pulitikal, ang kapamuhayan, ang mga sitwasyong nag-udyok ng karahasan, kadakilaan, kagitingan at kabayanihan ng isang tao o pangkat ng mga tao (Cole, 2018).

Ang mga teoryang nabanggit ay magiging gabay sa pagsusuri ng maikling kwento ni Fanny A. Garcia. Bibigyang-tuon ng teoryang marxismo ang mga tauhan sa akda, sisipatin ang tema gamit ang teoryang realismo, at gagamitin ang teoryang imahismo sa pagsuri sa mga simbolismo mayroon ang akda.

Sa pangkalahatan, ang pagsusuring ito ay naglalayong maipakita ang katotohanan at mga isyung pangkahirapan sa likod ng "Sandaang Damit" ni Fanny A. Garcia.

\subsection{Kahalagahan ng Pag-aaral}

Ang pag-aaral na ito ay mahalaga sa mga mag-aaral at mga guro lalo na sa mga nagpapakadalubhasa at nagtuturo ng kursong panitikan, nagpapakadalubhasa sa Filipino, at maging sa kahit sino sa lipunan. Magbibigay nang mas malalim na pag-unawa ang pagsusuring ito kung ano ang halaga ng isang damit sa tao batay sa sinuring akda. Magsisilbi itong daan upang makita ang reyalidad sa lipunan at makatutulong din upang mas mapaunlad ang kaalaman sa panitikan. Samakatuwid, magsisilbing gabay ang pag-aaral na ito tungo sa pagtuklas ng papel ng panitikan bilang instrumento ng pagpapahayag ng mga suliraning panlipunan.

\section{Metodolohiya}

Ang pagsusuring ito ay isang kwalitatibong uri ng pag-aaral na gumamit ng content analysis. Sinuri ng mga 
Canillas, K. I. R., \& Acala, M.

mananaliksik ang mga elemento at isyung pangkahirapan na nakapaloob sa "Sandaang Damit" ni Fanny A. Garcia. Nagsilbing tiyak na hakbang ang mga sumusunod:

Unang Hakbang. Elemento. Sa bahaging ito, sinuri ang mga tauhan, tema, at simbolismo sa akda. Gamit ang teoryang marxismo, pinag-aralan ng manunuri ang bawat tauhan na may mabigat na ginampanan sa akda at kung paano sila makatutulong upang ibunyag ang katotohanan sa likod ng sandaang damit. Sinipat naman ng manunuri ang temang napakapaloob sa akda gamit ang teoryang realismo. Sinuri ang akda batay sa temang ipinapahayag nito na may kaugnayan sa totoong mga pangyayari sa lipunan. Tinukoy at pinag-aralan din ng mga manunuri ang mga simbolismo na ginamit sa maikling kwento gamit ang teoryang imahismo. Sinuri ang mga ito batay sa kung paano ginamit ng manunulat upang ipahayag ang totoong mensahe ng maikling kwento

Ikalawang Hakbang. Isyung Pangkahirapan. Sa bahaging ito, binigyang-diin sa pagsusuri ang mga isyung pangkahirapan sa loob ng akda. Gamit ang teoryang sosyolohikal, pinag-aralan ng mga manunuri ang ugnayan ng mga isyung pangkahirapan sa akda sa uri ng lipunan na kinabibilangan ng may-akda.

\section{Resulta ng Pagsusuri}

Makikita sa bahaging ito ang resulta ng isinagawang pagsusuri gamit ang apat na mga teorya - marxismo, realismo, imahismo, at sosyolohikal.

Tauhan. Ang antas ng mga tao sa lipunan ay hindi pantay-pantay at iba-iba ang kinatatayuan ng bawat isa. Makikita sa sumusunod na talahanayang ang mga tauhan sa maikling kwento at ang kanilang inilalarawan gamit dulog marxismo.

\section{Talahanayan 1.1}

Mga Tauhan

\begin{tabular}{cl}
\hline Mga Tauhan & \multicolumn{1}{c}{ Katayuan sa Lipunan } \\
\hline Batang Babae & Ipinakikilala ang mga mahihirap sa lipunan ngunit \\
Mga Kaklase & nagpapakita ng pagsisikap na makaahon sa kahirapan. \\
& Inilalarawan nila ang mga taong nakaangat sa lipunan na \\
gusto lamang makisama sa mga taong pantay o higit pa sa & kanila ang pamumuhay. \\
Guro & Inilalarawan nila ang mga taong pantay lang ang katayuan \\
& sa lipunan. Hindi sila nasa laylayan ngunit hindi rin \\
& makalaban sa mga nakaaangat. \\
& Inilalarawan nila ang mga mangagawa nahit anong \\
pagsisikap sa paghahanapbuhay ay hindi pa rin umuunlad & ang pamumuhay at lugmok pa rin sa kahirapan. \\
\hline
\end{tabular}

Batang babae. Isa siyang perpektong karakter upang ilarawan ang mga taong nasa laylayan ng lipunan.

“Ang panunukso ng mga kaklase ay hindi nagwawakas sa kaniyang mga damit.”

“...ang kaniyang baon ay isa lamang pirasong tinapay na karaniwa'y walang palaman.”

Sa mga linyang ito sa simula ng kwento ay nagpapakita na ng isang normal na pagsasalarawan sa isang taong nasa pinakamababang antas sa lipunan - katukso-tuksong pananamit at halos walang makain.

"Hanggang isang araw ay natuto siyang lumaban."

“Mula noo'y naging kaibigan niya ang mga kaklase. Ngayo'y siya ang naging tagapagsalita at sila naman ang kaniyang tagapakinig. Lahat sila'y natutuwa sa kaniyang kuwento tungkol sa sandaang damit. Nawala ang kaniyang pagkamahiyain."

Ipinakita ng pangunahing tauhan ang kaniyang pagsubok na labanan ang katotohanan na siya ay kakaiba sa kaniyang mga kaklase. Sinubukan niyang pantayan ang mga nakaangat sa lipunan sa pamamagitan ng 
pagkwekwento.

“Ang natagpuan nilang bahay ay sira-sira at nakagiray na sa kalumaan.”

"Sumungaw ang isang babaeng payat, iyon ang ina ng batang mahirap. Pinatuloy sila at nakita nila ang maliit na kabuuan ng kabahayan na salat na salat sa anumang marangyang kasangkapan. At sa isang sulok ay isang lumang teheras at doon nakaratay ang batang babaeng may sakit pala."

Sa mga linyang ito nagsimulang lumabas ang katotohanan sa likod ng pangunahing tauhan. Ito ay pagpapatunay na walang kakayahan ang isang mahirap na baguhin nang ganoon kadali ang kanyang kinalalagyan sa lipunan. Sa pahayag ni Birchall (1997), ang mayayaman ang may kakayahang baguhin ang ganitong sistema at hindi ang mahihirap. Ang isang batang mahirap sa lipunang Filipino ay ang batang puno ng pangarap at ambisyon sa buhay. Ang tauhan sa kuwento ay kumakatawan sa mga kabataan na nasasadlak sa kahirapan ngunit nananatiling positibo sa buhay. Ang bata ay representasyon ng pagkakaroon ng positibong pananaw at kumakapit sa pangarap kahit sa imahinasyon lamang. Ang pagpapakita ng mga sitwasyon sa kuwento ng mga pangyayari na tinatawanan ang bata, walang baon, at sakitin ay pagpapahayag ng naidudulot ng kahirapan sa bawat kabataan. Ang pagbuo ng mga iginuhit na damit ay pagsasalarawan ng konsepto ng "kahit sa imahinasyon matupad". Ipinapakita lamang nito na ang bawat bata sa bansa ay may kani-kaniyang hangarin sa buhay ngunit ang kahirapan ay nagiging balakid upang matupad ito. May mga batang nagsusumikap, may mga nagtatrabaho, habang ang ilan ay pinipiling tanggapin ang kinasadlakan na kahirapan. Malinaw na ang kuwento ay isang instrumento upang ipamulat sa lahat na bawat bata ay may pangarap, mahirap man ngunit ang katuparan sa mga ito ay isang inaasam-asam na adhikain sa buhay.

Mga Kaklase. Ang uri ng tauhan na ginampanan ng mga kaklase ay ang popular na paglalahat na ang mga nasa itaas na antas ng lipunan ay may mababang pagtingin sa mga nasa ibaba.

“...ay masusulyapan niya ang mga pagkaing nakadispley sa ibabaw ng pupitre ng mga kaklase: mansanas, sandwiches, kending may iba-ibang hugis at kulay na pambalot na palara.”

Sa teoryang Marxismo, dito makikita ang malaking agwat ng mayayaman sa mahihirap.

“...at sila naman ang kaniyang tagapakinig. Lahat sila'y natutuwa sa kaniyang kuwento tungkol sa sandaang damit.”

“Naging masayahin siya bagaman patuloy pa rin ang kaniyang pamamayat kahit ngayo'y nabibigyan nila siya ng kapiraso ng kanilang baong mansanas o sandwich, isa o dalawang kendi.”

Kung susuriin ang pahayag ni Birchall (1977), ang mayayaman ang may kakayahang ayusin ang agwat sa lipunan. Sa mga linyang ito ay nagsimula na silang makisama sa batang babae sa kabila nang hindi nito pagbabago ng pananamit at pagkain.

Guro. Masasabing inilalarawan niya ang mga taong nasa gitnang katayuan sa lipunan. Sa kabila ng katotohanang walang malaking gampanin ang guro sa kwento bilang tauhan, masasabi pa ring ang kanyang karakter sa pagsusuri gamit ang marxismo ay walang nagawa upang alisin ang agwat sa lipunan. Ayon sa Marxist Social Hierarchy, ang mga nabibilang sa middle class ay walang sapat na kakayahan upang magkaroon ng mga sariling pag-aari o makabili ng serbisyo mula sa ibang tao. Sa kabilang banda, ipinagbibili nila ang kanilang serbisyo sa upper class upang kumita. Katulad ng mga nasa pinkamababang antas sa lipunan, kanila ring ipinagbibili ang kanilang kakayahan na sapat lamang upang maging komportable sa buhay ngunit hindi magawang maranasan ang karangyaan mayroon katulad ng mga nasa taas ng herarkiya (Marxist Social Hierarchy, Marxist on Social Class).

Ina at Ama ng Batang Babae. Maliban sa batang babae, ang mga tauhang ito ay naglalarawan din ng katayuan ng nasa pinakamababang antas sa lipunan. Ang ina ay naglalarawan sa mga taong walang hanapbuhay. 
Canillas, K. I. R., \& Acala, M.

Samantala, ang ama ay nagbibigay-katuturan sa isang mangagawa na nakabatay sa matataas na tao ang kikitain sa pang-araw-araw.

"Mapapakagat-labi ang kaniyang ina, matagal itong hindi makakakibo, at sabay haplos nito sa kaniyang buhok at paalong sasabihin sa kaniya, hayaan mo sila anak, huwag mo silang pansinin, hamo, kapag nakakuha ng maraming pera ang iyong ama, makakapagbaon ka na rin ng masasarap na pagkain, mabibili na rin kita ng maraming damit."

Sa kabila ng pagiging mulat sa katotohanan na sila ay mahirap, ibinahagi pa rin ng ina ang kaniyang pangarap para sa anak. Para sa isang tao na dumaranas ng kahirapan, walang ibang magagawa kundi ang magkaroon ng pangarap na maalis ang agwat ng kahirapan sa karangyaan o kahit sa simple at komportableng pamumuhay man lang.

“Ngunit ang ama'y hindi pa rin nakapag-uwi ng maraming pera kaya ganoon pa rin ang kanilang buhay.”

Sa mga linyang ito ipinakita ang katotohanan na hindi madali ang makaahon sa kahirapan. Ang mga magulang ng batang mahirap sa kuwento ay kumakatawan sa tipikal na magulang mula sa isang mahirap na pamilya. Dahil sa labis na kahirapan, walang ibang magawa ang magulang kundi ang tanggapin ang sitwasyon at magtrabaho sa abot ng makakaya. Ipinapakita rin sa kuwento na kahit ano pa ang iyong kagustuhan na makaahon sa kahirapan, dahil sa kakulangan ng pera at sa napakaraming pangangailangan ay hindi pa rin ito sapat. Samakatuwid, nais ipabatid ng kuwento na bawat haligi ng tahanan ay kailangang magkaroon ng sapat na mapagkukunan ng pera upang matustusan ang pangangailangan ng pamilya.

\section{Talahanayan 1.2}

Tema

\begin{tabular}{ll}
\hline \multicolumn{1}{c}{ Tema } & \multicolumn{1}{c}{ Pangyayari sa Realidad } \\
\hline Kahirapan & Matagal nang problema ng bansa ang ganitong isyu na \\
& patuloy lang na lumalala. \\
Diskriminasyon & Ito ay madalas mangyari sa mga paaralan na kung \\
& saan ang mahihirap na mag-aaral ay biktima ng \\
& pantutukso o bullying. \\
Kakulangan ng Atensyon sa Serbisyong & Ang pagpapagamot ay isang napakalaking hamon lalo \\
Pangkalusugan & na sa mga mahihirap. \\
\hline
\end{tabular}

Kahirapan. Sa ulat ng Philippine Statistics Authority (PSA), patuloy na tumataas ang bilang ng mahihirap sa bansa. Sa taong 2019, tumaas hanggang 30.9\% ang mga mangagawa na hindi sapat ang kinikita upang matugunan ang mga pangunahing pangangailangan ng pamilya. Ayon naman sa sarbey na isinagawa ng Social Weather Station (SWS), nagkaroon ng $45 \%$ pagtaas o 11.1 milyon ang mga nagsabing sila ay naghihirap sa kapareho pa ring taon (The Philippine Star, 2019).

Sa akda ay pinakabinigyan ng tuon ang tema ng kahirapan. Inilarawan ang mga tauhan sa pamamagitan ng pagkakaroon ng mahihirap na pamumuhay na makikita sa kanilang pananamit, pagkain, tirahan, at maging sa pangangatawan. Ipinaliwanag din ng akdang ito na ang kahirapan ay hindi matatapos kung ang isang miyembro lamang ng pamilya ang naghahanapbuhay.

Diskriminasyon. Sa pag-aaral ni Sanapo (2017), ang mga mag-aaral na Pilipino ay nakararanas ng diskirminasyon, panunukso, at pang-aapi dahil sa kanilang pananamit o katayuan sa lipunan. Napag-alaman ng Program for International Student Assessment (PISA) 2018 na 65\% mula sa 7,233 mag-aaral sa edad na 15 taon ang nakararanas ng ganitong suliranin sa paaralan noong 2018 (ABS-CBN News).

Sinimulan ang akda sa pagpakilala sa pangunahing tauhan bilang sumpungan ng tukso at katatawanan dahil sa kanyang pananamit at baong pagkain sa paaralan. Dito ay nagsimulang lumayo ang loob ng pangunahing tauhan sa mga iba pang tauhan sa kwento. 
"Malimit siyang nag-iisa. Laging nasa isang sulok. Kapag nakaupo na'y tila ipinagkit. Laging nakayuko, mailap ang mga mata, sasagot lamang kapag tinatawag ng guro."

Isinalaysay rin sa akda ang epekto ng diskriminasyon lalo na sa mag-aaral. Ito ay nagpapakita lamang na ang isyu ng diskriminasyon ay dapat nang bigyan ng pansin at aksiyon dahil sa kasalukuyang epekto nito sa mga biktima.

Kakulangan ng Atensyon sa Serbisyong Pangkalusugan. Sa pag-aaral ng European Union (2018) sa pangkalusugang serbisyo sa Pilipinas, natuklasan nila na ang pagbibigay ng tulong ng PhilHealth ay hindi pro-poor dahil sa hinihingi nitong Php30,000 kontribusyon. Ang mga lokal na pamahalaan naman ay hindi rin nakapagbibigay ng malaking suporta dahil sa kakulangan ng pondo para sa usaping pangkalusugan na kung saan ang mayayaman lamang na mga bayan o lungsod ang may kakayahang makatugon para sa pangangailangan na ito. Sa akda ay binigyan din ng pansin ang ganitong isyu sa lipunan.

\section{"At sa isang sulok ay isang lumang teheras at doon nakaratay ang batang babaeng may sakit pala."}

Dito ay masasalamin na ang katotohanan na ang mahihirap ay walang kakayahang makapagpagamot at mapipilitan na lang manatili sa pamamahay at lumala ang karamdaman. Ito ay dahil na rin sa kawalan ng sapat na serbisyo para sa mahihirap pagdating sa kalusugan at ang sariling suliranin sa pang-araw-araw na paghahanapbuhay.

\section{Talahanayan 1.3}

Simbolismo

\begin{tabular}{ll}
\hline \multicolumn{1}{c}{ Simbolismo } & \multicolumn{1}{c}{ Kahulugan } \\
\hline mansanas, sandwiches, kendi & $\begin{array}{l}\text { Simbolo ng pagkakaroon ng kaya sa buhay o pagiging } \\
\text { angat sa lipunan. }\end{array}$ \\
Limang piraso ng tinapay & Simbolo ng kahirapan. \\
Damit & Simbolo ng iba-ibang katayuan sa lipunan. \\
Sandaang damit & Simbolo ng mga pangarap. \\
Sandaan & Simbolo ng pagkakaroon. \\
Drowing & Simbolo ng katotohanan. \\
\hline
\end{tabular}

Mansanas, sandwiches, at kendi. Sa kwento, ginamit ito bilang palatandaan na ang tauhan na nauugnay dito ay nakaaangat sa lipunan kaysa sa iba. Sa kalagitnaan din ng kwento, ito ay nagsimulang maibahagi sa pangunahing tauhan na naglalarawan ng kahirapan. Isa itong patunay na ang katayuan sa lipunan o kayamanan ay maaaring ibahagi sa kapwa na nangangailangan nito.

Limang piraso ng tinapay. Salungat sa naunang simbolismo, ito naman ay nangangahulugan ng kahirapan. Ito ang ginamit na salita ni Garcia upang ilarawan at maipaliwanag ang kahirapan sa batang babae.

Damit. Ang simbolong ito ay ginamit upang maipaliwanag iba-ibang katayuan sa lipunan.

"Mayayaman sila. Magaganda at iba-iba ng kanilang damit na pamasok sa paaralan."

Sa linyang ito inilarawan na ang katumbas ng pagkakaroon ng iba-iba at magagandang damit ay ang pagkakaroon ng kayaman at pagiging angat sa lipunan.

“...sapagkat ang kaniyang damit, kahit nga malinis, ay halatang luma na, palibhasa'y kupasin at punung-puno ng sulsi.”

Sa bahaging ito ng akda ay ipinaliwanag din ang ang pagkakaroon ng luma, kupas, at pagkakapuno ng mga sulsi ng isang damit ay nangangahulugan ng kahirapan at pagiging kabilang sa mababang antas sa lipunan.

Sandaang damit. Ito ay pangarap ng batang babae. Sa pangkalahatan, hindi lamang pagkakaroon ng sandaang damit ang kaniyang pangarap kundi ang pagkakaroon din ng maayos na pamumuhay. 
Canillas, K. I. R., \& Acala, M.

“Alam n’yo,” aniya sa malakas at nagmamalaking tinig, “ako’y may sandaang damit sa bahay.”

“Mula noo’y naging kaibigan niya ang mga kaklase.”

Ginamit niya ang sandaang damit o ang kanyang pangarap upang paunti-unti ay matanggap sa katayuang hindi niya kinabibilangan.

Sandaan. Ito ay simbolo ng pagiging perpekto at pagkakamayroon. Mapamaraan at malikhain itong ginamit ng may-akda upang mas bigyan ng katuturan ang nais niyang ipahayag sa mga mambabasa. Isang pagsasalarawan ng kasaganahan na sa kwento ay nagsilbing pangarap ng pangunahing tauhan na gusto niyang maabot at magkatotoo.

Drowing. Isa itong simbolo na ginamit ng may-akda upang imulat sa katotohanan ang pangunahing tauhan pati na rin ang mga mambabasa.

"Sandaang damit na pawang iginuhit lamang."

Winakasan ang kwento gamit ang linyang ito upang magsilbing alaala na sa likod ng paghihirap at pangarap ay mayroong mas malalim na katotohanan. Ang mahirap ay maaaring magkunwari o magsinungaling sa kanyang lipunang ginagalawan ngunit lalabas pa rin ang katotohanan tungkol sa totoo niyang katayuan na dapat bigyan ng pansin ng nakararami.

Bilang kabuuan, ang manunulat ay gumamit ng iba-ibang tauhan upang ipakita ang iba-ibang katayuan o antas ng mga tao sa lipunan. Mas lalo ring binigyan ng halaga sa akda ang mga temang pumapaksa sa kahirapan, diskriminasyon, at isyu sa serbisyong pangkalusugan. Ang mga simbolismong ginamit ay nakatulong din upang mas lalong bigyang-diin ang nais ipahayag sa akda na tumutukoy sa iba-ibang katayuan sa lipunan, pangarap, at katotohanan.

Talahanayan 2

Isyung Pangkahirapan

\begin{tabular}{ll}
\hline \multicolumn{1}{c}{ Isyung Pangkahirapan } & \multicolumn{1}{c}{ Ugnayan sa Lipunang Pilipino } \\
\hline Kawalan ng trabaho & Pagtaas ng mga walang trabaho sa Pilipinas \\
Malnutrisyon & Kawalan ng atensiyon sa suliraning pangkalusagan \\
& para sa mahihirap \\
\hline
\end{tabular}

Kawalan ng Trabaho. Ang Sandaang Damit ay inilathala ng Unibersidad ng Pilipinas taong 2007. Ayon sa naging konklusyon ng pag-aaral nina Sibal et al. (2006), sa mga taong ito ay suliranin ng bansa ang globalisasyon na naging dahilan upang tumaas ang bilang ng mga walang trabaho at pagbaba ng sahod para sa mga manggagawa. Sa datos ng Philippine Statistics Authority, ang bilang ng mga walang trabaho noong Hulyo 2007 ay umabot ng 2.8 milyon o 7.8\%. Ang National Capital Region ay may unemployment rate na $13.1 \%$ at sa Central Luzon naman ay $11.5 \%$.

“...hayaan mo sila anak, huwag mo silang pansinin, hamo, kapag nakakuha ng maraming pera ang iyong ama, makakapagbaon ka na rin ng masasarap na pagkain...”

“Ngunit ang ama'y hindi pa rin nakapag-uwi ng maraming pera kaya ganoon pa rin ang kanilang buhay.”

Ang isyung pangkahirapan sa kawalan ng trabaho ay ipinakita ng may-akda sa pamamagitan ng pagbuo ng mga tauhan na humaharap sa kaparehong sitwasyon. Sa mga linyang ito, makikita na rin ang ugnayan ng lipunang ginagalawan ng may-akda sa kanyang isinulat. Mababatid rito na ang ina ng batang babae ay walang hanapbuhay at ang buong pamilya ay umaasa lamang sa isang mangagawa na kulang ang kinikita para sa pang-araw-araw na pangangailangan na isang malaking dahilan kung bakit hindi umuunlad ang kanilang pamumuhay. 
Malnutrisyon. Sa datos ng Food and Agriculture Organization of the United Nations (2010), ang ekonomiya ng bansa ay isang dahilan kung bakit umabot ng 28 milyong Pilipino ang walang kakayahang bumili ng kompleto at masustansiyang pagkain at ng iba pang pangunahing pangangailangan. Mula sa Global Study on Child Poverty and Disparities ng UNICEF, may $24.6 \%$ ang kulang sa timbang mula $0-14$ taong gulang noong 2005. Hindi rin ligtas sa malnutrisyon ang mga batang edad $11-19$ dahil 33 mula 100 ay kulang sa nutrisyon at hindi nasa tamang timbang.

"Kapag oras na ng kainan at labasan na ng kani-kanilang pagkain, halos ayaw niyang ilitaw ang kaniyang baon."

"Lumang damit. Di masarap na pagkain. Mahirap. Isinalaksak nila sa kaniyang isip."

Sa simula at pa lang ng kwento, binigyang-diin na ng may-akda ang kalagayang pangkalusugan ng batang babae. Ito ay dulot ng kakulangan sa masusustansiyang pagkain at maging ng iba pang mahalagang pangangailangan. Ang pangyayaring ito sa akda ay bunga ng nasasaksihan ng manunulat sa kanyang lipunan na kung saan ang malnutrisyon na dulot ng kahirapan ay isang malaking problema sa bansa.

"Sumungaw ang isang babaeng payat at iyon ang ina ng batang mahirap."

"At sa isang sulok ay isang lumang teheras at doon nakaratay ang batang babaeng may sakit pa la. Ngunit sa mga dumalaw ay di agad ang may sakit ang napagtuunang-pansin..."

Bago magtapos ang kwento, ipinakita rin ni Garcia ang problemang pangkalusugan ng ina ng batang babae. Siya ay inilarawan bilang payat at ina ng batang mahirap. Dito ay masasabing hindi lang ang batang babae ang naaapektuhan ng kahirapan kundi maging ang kanyang magulang. Isinalaysay din ang pagkakaroon ng sakit ng batang babae ngunit iba ang mas nakakuha ng atensiyon. Ito ay maaaring sumimbolo na ang mga isyung pangkalusugan para sa mahihirap ay hindi binigyan ng mas mabigat na pansin. Sa ilalim ng administrasyong Arroyo, sinasabing nagkaroon ng health insurance ang maraming Pilipino ngunit sa sarbey ng Social Weather Statation noong 2010, 36\% lang ay naisali sa PhilHealth at nanatili ang isyung pangkalusugan na pangunahing problema sa Pilipinas. Ayon na rin sa Malacañang, hindi naisali ang maralitang sektor sa pagpapatupad ng National Health Insurance Act of 1995 (PhilStar, 2011).

\section{Lagom ng mga Natuklasan at Konklusyon}

Batay sa resulta ng pag-aaral, ang akdang Sandaang Damit ni Fanny Garcia ay sumasalamin sa iba't ibang suliraning panlipunan kaugnay sa isyung pangkahirapan na kinakaharap ng bansa. Ang mga isyung ito ay iniuugnay sa kawalan ng trabaho ng mga Pilipino, problemang pangkalusugan, isyu ng diskriminasyon, at ang siwtasyon ng mga nasa mababang antas ng lipunan. Ang akda ni Fanny Garcia ay nagtataglay ng mga elementong pampanitikan tulad ng mga tauhan, tema, at simbolismo na nagsisilbing larawan ng katotohanan sa mga problemang kinakaharap ng mga mahihirap sa bansa. Ang mga tauhan tulad ng bata, guro, mga magulang, at kaklase ay representasyon ng iba't ibang uri ng tao na sangkot sa lipunang binubuo ng mga nakararanas ng kahirapan. Ang tema ng akda ay umiikot sa diwa ng kahirapan, diskriminiasyon, at isyung pangkalusugan. Binubuo rin ng mga simbolismo ang akda na mas nagbigay-imahen sa problemang pangkahirapan na dinaranas ng mga Pilipino. Samakatuwid, ang Sandaang Damit ni Fanny Garcia ay isang akdang pampanitikan na nagsilbing salamin ng isyung pangkahirapan sa bansa.

\subsection{Rekomendasyon}

Magsagawa ng iba pang pagsusuri sa mga akdang pampanitikan na repleksyon ng iba't ibang suliraning panlipunan. Sa pamahalaan, gumawa ng mga pagpaplano tungo sa implementasyon ng iba pang mga programa na tutugon sa problemang pangkahirapan ng bansa. Maglaan pa ng mas maraming oportunidad sa mga manggagawang Pilipino para magkaroon ng kita sa araw-araw ang bawat mahirap na pamilya. Paigitingin at dagdagan ang mga programang pang-edukasyon at pangkalusugan na naglalayong tumulong sa mga mahihirap 
Canillas, K. I. R., \& Acala, M.

na kabataan. Mahalaga rin ang pagpapatupad ng mga batas at programa na poprotekta sa bawat mamamayang Pilipino laban sa iba't ibang diskriminasyon sa lipunan.

\section{Sanggunian}

Belvez, P. M., Iliscupidez, P. P., Roberto, R. R., Pleno, N. F., Atienza, S. S. (2006). Panitikan ng lahi. Sampaloc, Manila: Rex Book Store, Inc.

Birchall, I. (1977). Marxism and Literature. The Sociological Review. Retrieved from https://doi.org/10.1111\%2Fj.1467-954X.1977.tb03233.x

Chen, L. M. (2015). Self-reported frequency and perceived severity of being bullied among Elementary School Students. Journal of School Health. 85, 587-594. Retrieved from https://doi.org/10.1111/josh.12289

Cole, N. L. (2018). Introduction to the sociology of knowledge. Retrieved from https://www.thoughtco.com/sociology-of-knowledge-3026294

Domingo, K. (2019). 6 in 10 Pinoy teens bullied in school: study. ABS-CBN News. Retrieved February 21, 2021 from https://news.abs-cbn.com/news/12/14/19/6-in-10-pinoy-teens-bullied-in-school-study

Escudero, M. (2019). Pamilya na nagsabing mahirap sila, dumami -SWS. The Philippine Star. Retrieved from https://www.philstar.com/pilipino-star-ngayon/bansa/2019/07/21/1936510/pamilya-na-nagsabing-mahir ap-sila-dumami-sws

European Union (2018). The Philippines health system review. Health systems in transition (Vol. 8 No. 2). Retrieved from https://apps.who.int/iris/bitstream/handle/10665/274579/9789290226734-eng.pdf

Fleming, L. C., \& Jacobsen, K. H. (2009). Bullying among middle-school students in low and middle income countries. Health Promotion International, 25, 73-74. Retrieved from https://doi.org/10.1093/heapro/dap046

Food and Agriculture Organization of the United Nations (2010). Nutrition and Consumer Protection. Retrieved from https://www.fao.org/ag/agn/nutrition/phl_en.stm

Gabiana, Myra. (2017). Bullying in a public elementary school of countryside Philippines. Journal of Academic Research. Retrieved from https://tinyurl.com/2hsmm8s8

Kao, J. T. \& Jurafsky, D. (2015). A computational analysis of poetic style imagism and its influence on modern professional and amateur poetry. Linguistic Issues in Language Technology. CSLI Publications.

Retrieved from https://aclanthology.org/2015.lilt-12.3/

Marxist Social Hierarchy. (2017). Marxist on Social Class. Retrieved from https://www.hierarchystructure.com/marxist-social-hierarcHy/

Panganiban, J. V., Panganiban, C. T., Matute, G. E., \& Kabigting, C. E. (2000). Panitikan ng Pilipinas. Sampaloc, Manila: Rex Book Store, Inc.

Pedroche, A. G. (2011). Tunay na health care ng masa ang kailangan. PhilStar Global. Retrieved from https://www.philstar.com/opinyon/2011/07/13/705170/tunay-na-health-care-ng-masa-ang-kailangan

Philippine Statistics Authority. (2007). Employment Rate Registered at 92.2 Percent in July 2007 Results from the July 2007 Labor Force Survey (LFS). Retrieved September 21, 2021 from https://tinyurl.com/mrd3h7uz

Philippine Statistics Authority. Working poverty rate: Mahirap ka pa rin ba kahit may trabaho? Retrieved from https://psa.gov.ph/sites/default/files/attachments/9_working\%20poverty\%20rate.pdf

RTaghizadeh, A. (2014) A theory of literary realism. Theory and practice in language studies. Finland: Academy Publisher. Retrieved from September 27, 2021 from https://tinyurl.com/rt8kda2a

Sanapo, M. (2017). When Kids Hurt Other Kids: Bullying in Philippine Schools. Psychology, 8, 2469-2484. Retrieved from https://doi.org/10.1111\%2Fj.1467-954X.1977.tb03233.X

Sibal, J., Amante, M., at Tolentino, M. C. (2006). Globalization and changes in work and employment conditions in the Philippines. School of Labor and Industrial Relations. University of the Philippines, Diliman, Quezon City, p. 8. Retrieved from https://tinyurl.com/2p8rn4ec

UNICEF. (2010). National Report Philippines. Global study on child poverty and disparities. The case of the Philippines. Retrieved from https://tinyurl.com/yckzprt5

108 Consortia Academia Publishing (A partner of Network of Professional Researchers and Educators) 